\title{
REVIEW
}

\section{Measurement of kidney perfusion in critically ill patients}

\author{
Antione G Schneider, ${ }^{1,3}$, Mark D Goodwin'2, Rinaldo Bellomo 1,3* \\ This article is one of ten reviews selected from the Annual Update in Intensive Care and Emergency Medicine 2013 and co-published as a series \\ in Critical Care. Other articles in the series can be found online at http://ccforum.com/series/annualupdate2013. Further information about the \\ Annual Update in Intensive Care and Emergency Medicine is available from http://www.springer.com/series/8901.
}

\section{Introduction}

Acute kidney injury (AKI) is a major complication of critical illness [1] occurring in 30 to $40 \%$ of all critically ill patients and in its severe form requires renal replacement therapy (RRT), in approximately $5 \%$ of patients [2]. AKI has been shown to be an independent predictor for mortality [3] and is associated with invasive therapy and substantial costs [4].

Despite its importance, the pathophysiology of AKI is still poorly understood. AKI is most commonly associated with systemic diseases, such as septic shock, major surgery and cardiogenic shock [1], but a specific mechanism causing AKI to develop in specific patients can rarely be determined. Since the early description of an "acute uremia syndrome" in crush injury victims during World War II [5,6] and its association with histopathological findings similar to those found in experimental renal artery ligation, ischemia or some form of alteration in renal blood flow has been thought to play a pivotal role in the pathogenesis of AKI. This paradigm that essentially all AKI in critically ill patients is the result of some form or degree of ischemia remains of continuing conceptual dominance to this day [7]. Despite such dominance, there are only very limited data supporting this concept. In a recent systematic review, Prowle et al. [8] highlighted the extraordinary fact that renal blood flow measurement, irrespective of the technique used, has only been reported in 46 critically ill patients (five studies) within the last sixty years. Thus, our knowledge, understanding, and theoretical constructs regarding global renal perfusion in critically ill patients with RRT-treated AKI (an estimated $5 \%$ of all ICU admissions for a total of approximately a quarter of a million such patients each year in developed countries alone) is, like an inverted pyramid, based on extremely weak evidence.

*Corresponding author: rinaldo.bellomo@austin.org.au

'Department of Intensive Care, Austin Health, Heidelberg, Melbourne, Australia

Full list of author information is available at the end of the article
Furthermore, given the complex and heterogeneous nature of the renal vasculature, evaluating the flow in the main renal arteries (macrocirculation) might not provide sufficient information to adequately understand perfusion alterations in complex diseases, such as septic or cardiogenic shock. Indeed, some pathophysiological processes may be associated with increased global renal blood flow $[9,10]$ despite loss of function. In such instances, there is experimental evidence that, at least in sepsis, this phenomenon may be caused by intra-renal shunting [11]. Hence, correlation between macroscopic renal blood flow and function is far from linear. Therefore, techniques allowing the study of microcirculatory parameters, such as cortico-medullary perfusion ratio and regional tissue oxygenation measurement, and assessment of their relative change over time may be more valuable in increasing our understanding of the pathophysiology of AKI.

In this state-of-the art review, we discuss the value, challenges, limitations, safety and feasibility of different techniques for the measurement of kidney perfusion in critically ill patients. The advantages of each technique will be weighed against its disadvantages in the context of the critically ill patient with AKI. Particular emphasis will be placed upon techniques enabling some evaluation of the microcirculation, because emerging experimental evidence suggests that these are the techniques that are the most likely to improve our understanding of the disease and help clinicians develop and apply physiologically logical interventions.

\section{Non-imaging methods for renal blood flow quantification}

Microsphere deposition methods

Microsphere distribution methods [12-14] can provide very detailed information on regional perfusion between and within organs. After intravascular injection of radioactively labeled microspheres, their tissue deposition is 
proportional to blood supply. Several tracers can be used to evaluate changes after pharmacological intervention. The tissue needs to be harvested and sectioned to allow measurement of radioactivity, which is proportional to the quantity of microspheres deposited and, hence, to the organ perfusion [15]. Results are typically reported in 'flow per gram of whole tissue.' This method is obviously limited to animal research as it involves tissue collection. It is, however, very often used as a comparator in studies validating organ flow measurement.

\section{Paraamino-hippurate clearance}

The classic physiological method to estimate renal plasma flow is by calculation of paraamino-hippurate (PAH) clearance. $\mathrm{PAH}$ is an amide derivative of the amino acid glycine and para-aminobenzoic acid. PAH is almost fully removed from the plasma during its first pass though the kidney. Its renal clearance can, therefore, be used as an estimate of the renal plasma flow (ERPF). Typically, this technique involves a bolus followed by a continuous infusion of PAH. PAH concentration is then measured in blood and urine samples. ERPF is then calculated using the classic clearance formula ( $\left.\mathrm{RPF} \sim \mathrm{Cl}_{\mathrm{PAH}}=\mathrm{U}_{\mathrm{PAH}} \times \mathrm{V} / \mathrm{P}_{\mathrm{PAH}}\right)$.

Unfortunately, PAH is not used in clinical practice as the chemical analysis procedure is very cumbersome, not widely available and cannot provide information in 'realtime. Additionally, as they rely on urine concentration measurement, PAH clearance methods cannot be applied in oligo-anuric patients and its non-invasive use in AKI is, therefore, limited. On the other hand, PAH clearance can be used to measure ERPF for research purposes even in oligo-anuric patients. Such measurement, however, becomes invasive and requires renal vein canulation and sampling.

\section{Renal vein thermodilution methods}

Renal thermodilution methods were first described in the 1970s [16,17], but have gained increased attention in critically ill patients more recently $[18,19]$. These methods involve the insertion of an indwelling catheter into one of the renal veins. Renal blood flow calculation is based on measured changes in temperature of the renal vein blood after injection of a bolus of isotonic saline at room temperature [19]. Using such methods, Ricksten et al. have conducted several elegant studies of global renal perfusion in cardiac surgery patients [20-22]. For example, they demonstrated that restoring mean arterial pressure (MAP) from 60 to $75 \mathrm{~mm} \mathrm{Hg}$ improved the renal oxygen supply/demand relationship after cardiac surgery in patients with vasodilatory shock and AKI [21]. This technique, however, remains highly invasive and, because of the risk of renal vein thrombosis, can only be applied for a limited period of time.

\section{Xenon washout}

Xenon washout techniques were used for research purposes in the seventies [23]. This invasive technique relies on intra-arterial injection of a radioactively marked tracer $\left(\mathrm{Xe}^{133}\right)$ and external counting with a scintillation probe. Mean renal blood flow is calculated from the initial slope of the disappearance curve. This method was very useful to establish renal vasculature reactivity to different pharmacologic agents $[24,25]$. However, it has currently been replaced by less invasive, more precise imaging techniques.

\section{Intravascular Doppler}

Blood flow velocity can be evaluated invasively using an intra-arterial Doppler wire. This technique enables calculation of renal blood flow provided that the diameter of the vessel can be estimated [26]. Accurate measurements can be made in small straight tubes $(<4.76 \mathrm{~mm})$ and if the flow rate is $<200 \mathrm{ml} / \mathrm{min}$ [27]. The utility of this technique in humans, in whom renal blood flow is typically in the range of $300 \mathrm{ml} / \mathrm{min}$, is therefore limited. Similarly, this technique cannot account for the presence of collateral vessels and can, therefore, grossly underestimate flow.

Given these technical limitations and its invasiveness, intravascular Doppler is not currently applicable to critically ill patients even in the setting of a research protocol. It can be used as a comparator in animal studies in order to validate newer methods.

\section{Nuclear medicine techniques Scintigraphy}

Scintigraphy relies on the injection of radiolabeled isotopes and the capture of the emitted radiation by external gamma cameras generating 2D images. Using isotopes such as iodine-131 $\left.{ }^{131} \mathrm{I}\right)$ coupled to orthoiodohippurate $(\mathrm{OIH})$, scintigraphy is able to accurately quantify renal blood flow. This technique can be coupled with simultaneous measures of glomerular filtration rate (GFR) with the ability to determine relative function for each kidney.

Several isotopes have been used and although ${ }^{131} \mathrm{I}$ labeled OIH still represents the gold standard for renal blood flow quantification, it is not used clinically because it is associated with high radiation exposure, particularly in patients with renal failure. Therefore, $99 \mathrm{mTc}$ mercapto-acetylglycyl-glycyl-glycine $\quad{ }^{99 \mathrm{~m} T c-M A G 3)}$ is currently the marker of choice for this purpose $[28,29]$. This molecule is mainly excreted via tubular secretion at the distal part of the proximal tubule with a very high first-pass elimination [30]. Semi-quantitative measurement of renal blood flow can be obtained using the firstpass time-activity curve generated from a region of interest over the kidney [31]. Other techniques expressing renal blood flow as a fraction of cardiac output 
have been proposed [32]. Because of its high and unpredictable (75-90\%) plasma protein binding properties, ${ }^{99 \mathrm{~m} T c-M A G 3}$ based techniques are not as accurate as those based on ${ }^{131} \mathrm{I}$-OIH $(75-90 \%)$ to estimate renal blood flow [33]. In addition, ${ }^{99 \mathrm{~m} T c-M A G 3}$ is not purely eliminated by the renal route and the percentage eliminated via the hepatobiliary pathway increases in renal dysfunction. Other technetium based molecules (99mTc-Ethylene-l-dicysteine [99mTc-EC] or [99m] Tc-tricarbonyl nitrilotriacetic acid [99mTc(CO)3NTA]) [34] with lower hepatobiliary elimination and higher kidney to background ratio have been proposed.

Overall, 99mTc-diethylenetriaminepentaacetic acid (DTPA) is most commonly used for GFR measurement. It delivers slightly lower values as compared with standard inulin clearance but is easier to prepare and more readily available. However, the results generated by the so-called Gates methods [35] have not been shown to be superior to creatinine-based formulas [36].

Renal scintigraphy finds most of its clinical application in renal transplantation medicine. In this context, it can help differentiate acute tubular necrosis from transplant rejection [31]. In AKI, renal scintigraphy is usually of little value for the identification of the mechanism of renal dysfunction, although some patterns can be identified (ureteric obstruction, ischemia) [37]. Renal scintigraphy can be used to determine the symmetry of the disease and provide information on organ size and overall perfusion. Unfortunately, it does not provide information on intra-renal flow distribution.

\section{Positron-emission tomography}

Positron-emission tomography (PET) scans rely on the injection of a positron-emitting isotope tracer, such as 18-fluorine in the most commonly used PET tracer, 18-F fluorodeoxyglucose (FDG). Many other isotopes also emit positrons, including rubidium-82, 11-carbon and 15-O labeled $\mathrm{H}_{2} \mathrm{O}$. The emitted positron interacts with an electron, emitting a pair of high-energy photons in the annihilation process. These photons are detected by scintillators in the scanner generating 3D images. PET can be coupled with computed tomography (CT) and can then provide significantly better spatial resolution than scintigraphy alone.

Two fundamental approaches have been proposed to measure renal perfusion with PET: Dynamic imaging following bolus injection and static imaging at steady state using an ultra-short-lived tracer. The first technique makes use of a highly extracted blood flow tracer such as rubidium-82 [38]. This method has been used in animal models of renal artery obstruction, occlusion and reperfusion [39]. The second technique makes use of ultrashort-lived tracers, such as oxygen-15-labelled water (half-life of $2 \mathrm{~min}$ ) [40]. This compound was studied by
Juillard et al. [41], who showed an excellent correlation with microsphere techniques in an animal model and by Alpert et al. [42], who used O-15 water to measure renal blood flow in healthy volunteers. Other potential applications include measurements of renal blood flow in renovascular disease, in rejection or in acute tubular necrosis of transplanted organs, in drug-induced nephropathies, ureteral obstruction before and after revascularization and before and after placement of ureteral stents [40].

Despite its theoretical large potential, there has been very little use of PET in functional imaging. More importantly, its use in critically ill patients is likely to be very limited even for research purposes. Indeed, PET protocols are long and require extensive mobilization, which, in unstable patients is often labor intensive and can be associated with safety hazards. This adds to the general limitations associated with the difficulty of producing and handling non-standard tracers, their cost and the requirement for many of them for a nearby cyclotron (because of their extremely short half life). Finally, PET involves radioactivity exposure (although minimal), which might make acceptance by ethics committees, next of kin or ICU staff more difficult in the context of a clinical study.

\section{Magnetic resonance imaging}

Magnetic resonance imaging has gained immense popularity over the last few decades as it allows generation of very high-resolution images, including $3 \mathrm{D}$ reconstructions, without ionizing radiation. Imaging is based on the imaging of protons, using measurement of a radiofrequency signal emitted by protons regaining their thermodynamic equilibrium after their spins have been aligned in a large magnetic field. Protons in different tissues return to their equilibrium state at different relaxation rates.

Among the numerous MRI techniques available, some enable renal blood flow quantification and, importantly, some enable a degree of parametric mapping of intraorgan blood flow distribution or tissue oxygenation. These properties make MRI very appealing to study renal perfusion alterations in critical illness. Unfortunately, these approaches are likely to be limited to research protocols as they involve a lengthy and potentially hazardous transfer, considerable costs and are limited by the availability of MRI machines.

\section{Contrast-enhanced MRI modalities}

MRI based perfusion studies have classically been based on contrast-enhancement by gadolinium-based solutions. Gadolinium agents produce contrast on MRI scans because gadolinium is a paramagnetic substance, which therefore has a marked local effect on the speed at which adjacent protons return to their thermodynamic 
equilibrium. Fast acquisition techniques allow sufficient temporal resolution to monitor intra-renal signal changes during first pass of the agent. Approaches have been described [43] enabling quantification of absolute cortical and medullary perfusion. This would make gadoliniumbased MRI technology of great interest for the assessment of renal perfusion.

Unfortunately, the discovery of nephrogenic systemic fibrosis and its probable association with gadolinium accumulation in renal failure (acute or chronic) [44] greatly limits its interest in AKI and critically ill patients. The warnings for gadolinium contrast agents have recently been updated and three agents are currently contraindicated in patients with AKI or with chronic renal impairment and a GFR $<30 \mathrm{ml} / \mathrm{min}$. The other agents do not have this contraindication although extensive precautions are still advised [45].

Newer contrast agents based on ultra-small particles of iron oxide (USPIO) molecules have been presented and seem to be safe and potentially useful for renal blood flow measurement [46]. However, their safety profile is not yet fully established and their clinical role is still to be established, in particular since other MRI techniques, which do not need intravenous contrast agents, are now available.

\section{Cine phase-contrast MRI}

Cine phase-contrast MRI is a magnetic resonance angiographic technique that allows measurement of renal flow in both renal arteries without a contrast agent. Central to the technique is the fact that protons that are moving along the direction of a magnetic field gradient receive a phase shift proportional to their velocity: Static protons are unaffected and receive no phase shift, but moving protons will have their phase changed. The amplitude of this change is dependent on the velocity of the proton. Phase-contrast MRI has been very well validated to measure aortic flow rate but less so for renal arteries because of their small size and issues related to respiratory movements [47-49] (Figure 1).

Renal blood flow measurements by cine phase-contrast MRI are well correlated with simultaneous PAH clearance measurement [50] and the results are reproducible [51]. King et al. [52] used this method as a tool to predict clinical response after percutaneous angioplasty in renal artery stenosis. This technique has recently been used in critically ill patients to determine renal blood flow in sepsis [53]. To the best of our knowledge, this study was the first to measure global renal blood flow noninvasively in critically ill patients with sepsis associated AKI. Values for renal blood flow varied markedly from 392 to $1,337 \mathrm{ml} / \mathrm{min}$ (normal values range according to size and cardiac output from 800 to $1,200 \mathrm{ml} / \mathrm{min}$ ). This study provided a clear demonstration that, in septic critically ill patients with AKI, renal blood flow can range from low to supranormal and confirmed what animal studies had long suggested: Septic AKI is not a uniform disease and is not reliably associated with decreased renal blood flow (so-called ischemia). Even more importantly, and in keeping with experimental observations, these values correlated well with the patient's cardiac index and renal vascular resistance but not with the patient's GFR. This clear dissociation between global perfusion and global function is important because it implies changes in microvascular perfusion (shunting or changes in intraglomerular pressure dynamics or both).

\section{Arterial spin labeling}

Arterial spin labeling (ASL) is an MRI modality typically used for cerebral perfusion studies [54]. In an analogy with cine phase-contrast techniques, ASL uses blood as an endogenous contrast agent. Blood flowing towards a tissue is selectively labeled to have an opposite magnetization compared to this tissue. A perfusion-weighted image can be produced by subtracting an image in which inflowing spins have been labeled from an image in which spin labeling has not been used (Fig. 2). [55]. ASL allows imaging of the renal arteries despite their complex orientation [56]. A fairly good correlation of ASL with PAH clearance has been reported [57] and some applications after renal transplantation or in renal artery stenosis $[55,58]$ have been proposed. One of the main interests of ASL is its ability to draw parametric maps of relative perfusion (Figure 2) enabling clinicians to study geographical intra-organ differences in perfusion as opposed to overall organ blood flow. All pixels in a specific tissue can be averaged to provide mean perfusion. Such maps could enable the study of differential perfusion between cortex and medulla in critical illness and to identify ischemic and hyperemic areas within the kidney.

\section{Blood oxygen level-dependent (BOLD) MRI}

BOLD MRI takes advantage of the different magnetic properties between oxygenated and deoxygenated hemoglobin. Oxyhemoglobin (the principal form found in arterial blood) has no major magnetic properties, but deoxyhemoglobin is strongly paramagnetic, generating local magnetic field inhomogeneities corresponding to an increase in relaxivity defined as $\mathrm{R} 2 \%$. The amount of deoxyhemoglobin functions as a biological contrast agent and can be related to the strength of $\mathrm{R} 2 *$ weighted pulse sequences. BOLD MRI generates images, the signal intensity of which is a reflection of tissue metabolism representing the balance between oxygen consumption and delivery. Relatively low spatial resolution is a problem inherent to the technique.

BOLD enables the generation of parametric maps (Figure 3 ) of oxygenation in the kidney as illustrated by 

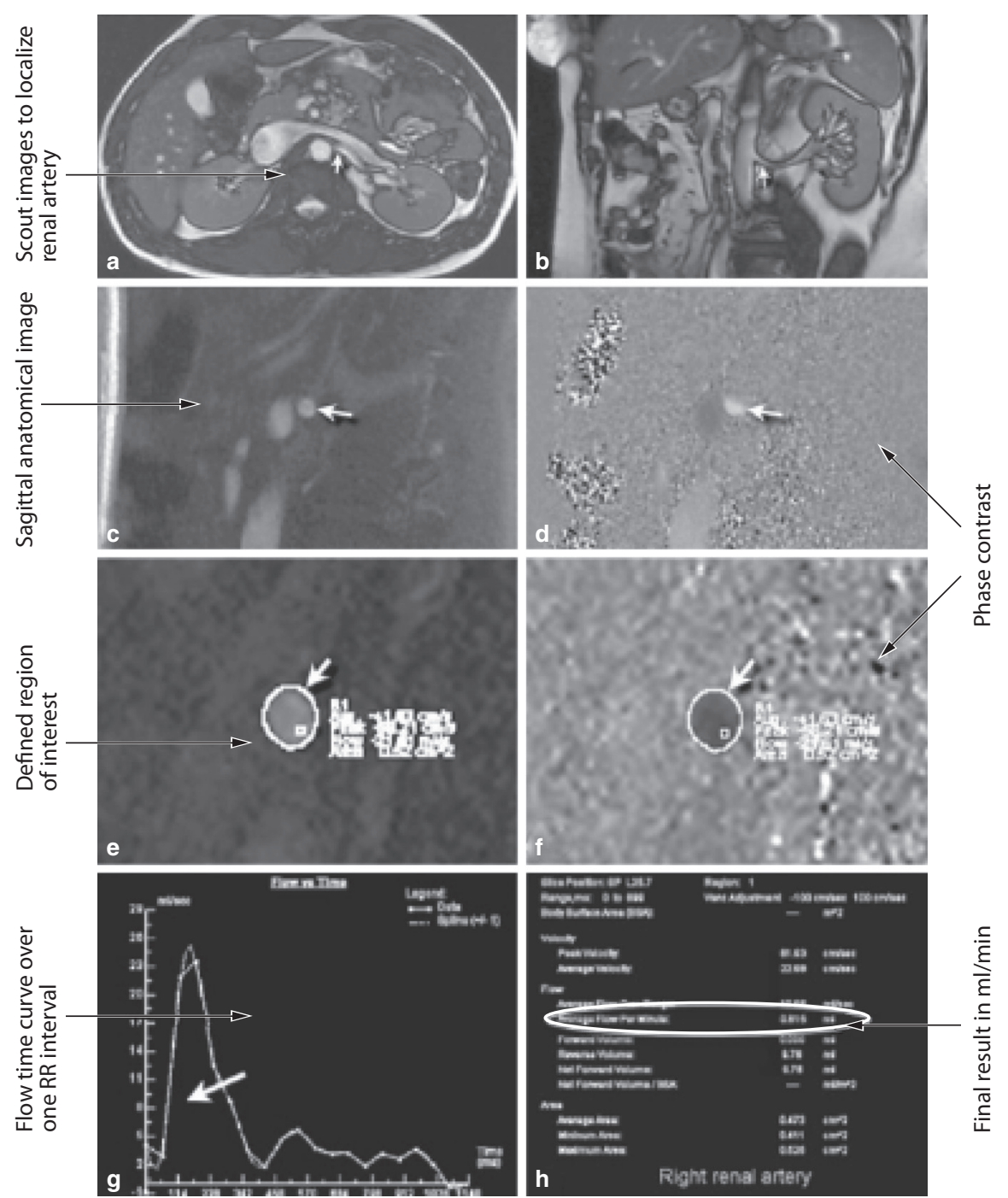

Figure 1. Cine phase-contrast imaging. (a) and (b) Initial acquisition of scout images enabling localization of renal arteries (white arrows); (c) Sagittal image of the renal artery on phase compensated image (white arrow); (d) phase contrast image of the renal artery (white arrow) at the same level; (e) and (f) magnified views of (c) and (d) where the investigator has placed a region of interest over the renal artery; (g) time intensity curve for one RR interval; h: the area under the curve multiplied by the heart rate approximates the renal blood flow.

Textor et al. [59] in kidneys with renal artery stenosis. This technique has been used to demonstrate an increase in tissue oxygenation after administration of diuretics, particularly in the medullary areas and confirmed by implanted oxygen probes [60]. Similarly, Pruijm et al. [61], showed an increase in medullary oxygenation in healthy volunteers after a decrease in their salt intake. Although not a direct measure of renal blood flow, BOLD MRI might deliver valuable information as it delivers data integrating oxygen delivery and consumption.

Although the various MRI-based techniques discussed above offer promise in our ability to investigate changes in renal perfusion in critically ill patients, it is difficult to imagine how they could be widely applied at this stage. The MRI environment is hostile to the critically ill and carries some significant safety concerns during transport and during a prolonged period in the magnet. In addition, obtaining high quality MRI scans in the critically ill is also often very challenging. The high cost adds a further degree of difficulty, which makes repeated assessment logistically very difficult.

\section{Ultrasonography}

Ultrasonography is the most commonly used imaging modality in the initial evaluation of patients with acute or chronic kidney diseases. It is widely available, easy to use, free of complication and can be performed at the bedside.

Standard ultrasound provides information on kidney size (a small kidney suggests possible atrophy in the context of chronic kidney disease, a large kidney might 

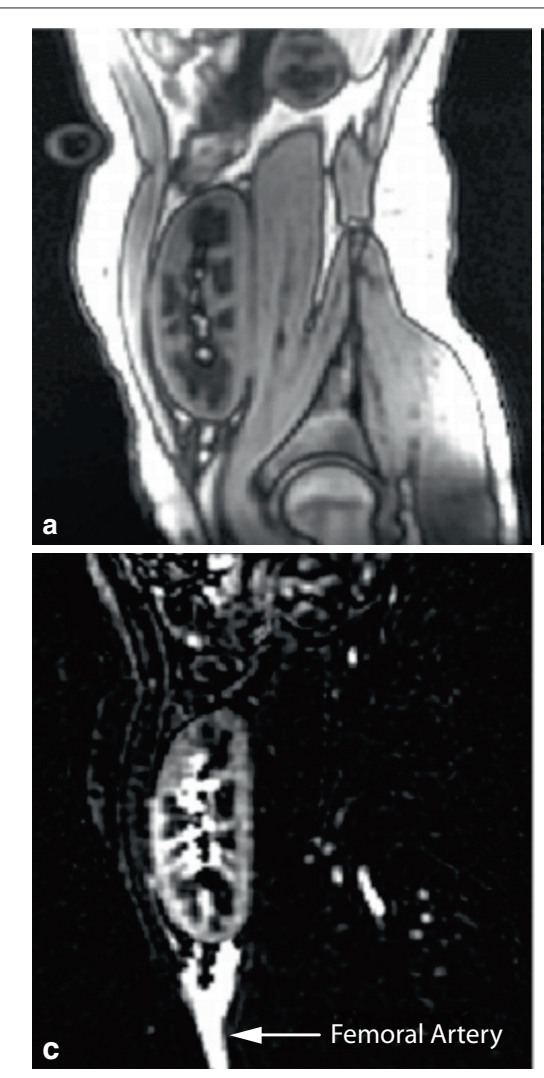

Figure 2. Arterial spin labeling in a transplant kidney. Tagged image (a) with moving spins labeled; control image (b); difference between a and $\mathrm{b}$ representing the perfusion-weighted image (c); and resulting perfusion map (d) shown in units of $\mathrm{ml} / \mathrm{min}$ per $100 \mathrm{~g}$ (adapted from [55] with permission). suggest the presence of infiltrative disease), cortical thickness and echogenicity and enables imaging of the excretory tract to diagnose outflow obstruction. In AKI, however, standard ultrasound examination is normal most of the time. Assessment of renal perfusion by ultrasound can be approached by Doppler techniques or with microbubble-based contrast agents (contrast-enhanced ultrasound).

\section{Doppler ultrasound}

Conventional ultrasound can be enhanced by using the Doppler effect. The Doppler effect occurs because the frequency of a reflected sound wave changes according to whether it is moving towards the ultrasound probe or away from it. The speed and direction of flow in a specific scanned volume can be calculated. Doppler ultrasound enables the generation of time-velocity curves from which peak systolic and end-diastolic velocities can be obtained. Based on these values different indices can be calculated and associated with a measurement of the renal artery diameter, renal blood flow can be estimated. The most commonly reported index is called the resistive index (RI). RI is calculated according to the formula:
RI = (peak systolic velocity - lowest diastolic velocity)/ peak systolic velocity

These measurements, however, have several limitations: Measurements are sensitive to numerous parameters, such as vessel stiffness, heart rate (increased rate over-estimates end diastolic velocity), heart rhythm (difficult to obtain reliable values during atrial fibrillation), external compression by transducer (in particular in a transplanted kidney) or Valsalva maneuvers that can decrease flow velocity [62]. These indices were poorly correlated with invasive measurement of renal blood flow in a sheep model [63]. However, Lerolle et al. demonstrated that Doppler indices on admission could predict AKI in critically ill patients [64]. Unfortunately, because of the way it is calculated, an increased RI may indicate the presence of increased renal vascular resistance with decreased flow or the presence of normal renal resistance with increased flow or even the presence of decreased resistance with markedly increased flow. Ureteric obstruction also significantly affects measurement of RI. The RI alone is, therefore, easily confounding. 

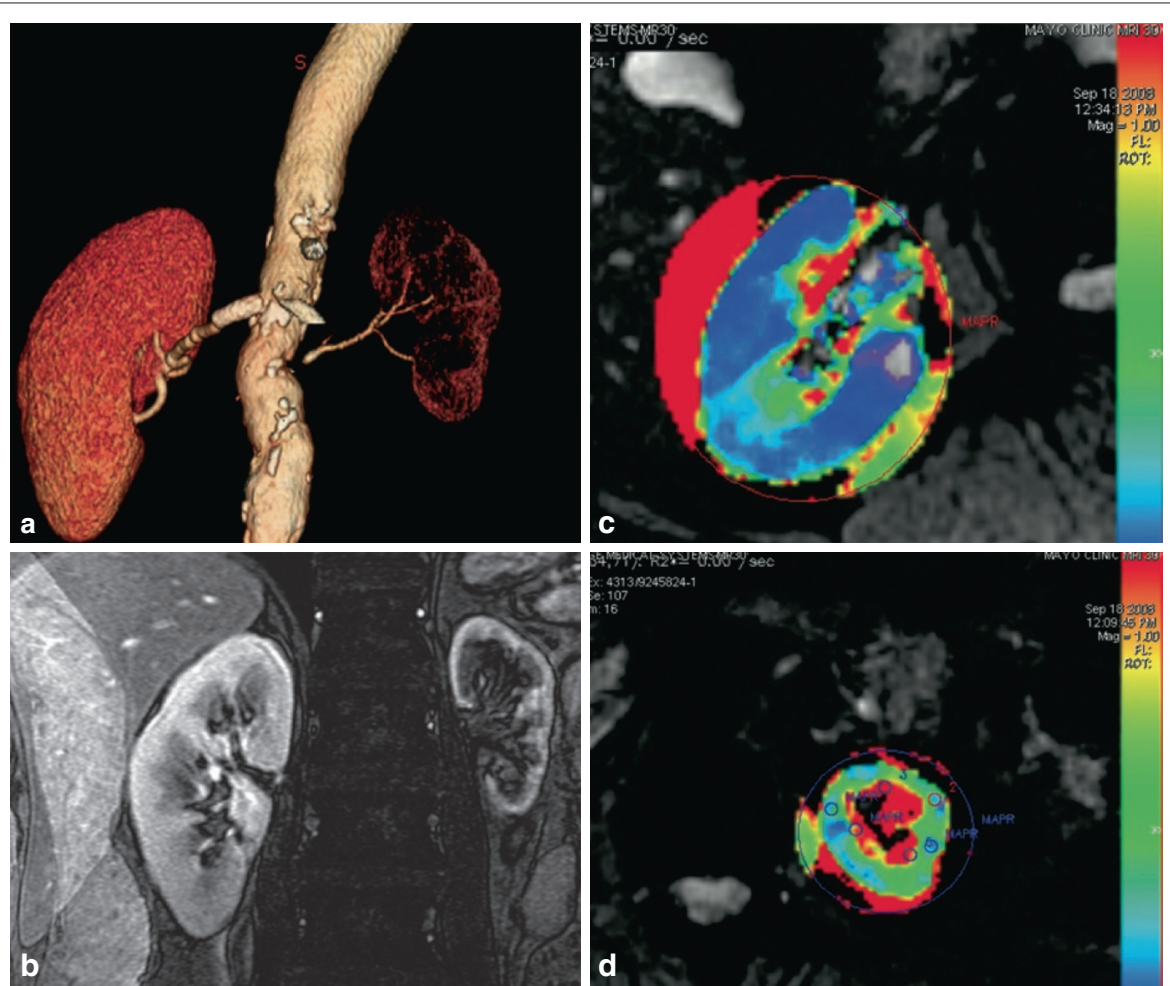

Figure 3. Blood oxygen level-dependent magnetic resonance imaging (BOLD MRI) in severe occlusive disease of the left kidney.

T2 imaging by CT angiogram (a) and T2 MRI (b) demonstrating severe renal-artery stenosis (left kidney) and presence of a stent in the contralateral kidney. (c) and (d) Parametric maps of R2* (reflecting the deoxyhemoglobin level) from BOLD MRI in the same patient. In the right kidney

([c] normal, well-perfused), most of the cortex shows low R2* signal (blue) and there are some small areas with a high R2* signal in the medulla (red). Conversely, in the left kidney ([d] vascular compromise), there are higher levels of cortical R2* indicating the presence of more deoxygenated blood and a large, deep area with a high R2* signal (deoxygenated hemoglobin) in the medulla (from [75] with permission).

Ultrasound-Doppler studies are routinely performed during the follow-up of renal transplant patients where the absence of a decrease of RI could be a sign of early rejection [65].

Altogether, ultrasound-Doppler has many advantages, is non-invasive, can be performed at the bedside, and can be repeated to evaluate changes after an intervention. However, ultrasound-Doppler is inherently patient- and operator-dependent. Its overall reliability and the relationship between derived indices and renal perfusion require further investigation.

\section{Contrast-enhanced ultrasound}

Gases are ideal contrast agents for ultrasonography as they are highly compressible and their density is 1,000-fold less than blood. Embedded within a shell they can be made to form microbubbles [66], which are extremely potent ultrasound reflectors. Microbubbles change shape when they interact with ultrasound waves resulting in the generation of non-linear signals. Microbubbles can be obtained rapidly by agitating saline. Such microbubbles are used to diagnose right-to-left shunt during cardiac echocardiography. However, these bubbles are very heterogeneous in size and shape, their half-life is very short and they can be associated with cerebral ischemic events [67].

In the last decade, commercial preparations of contrast agents for ultrasound have become available. These agents demonstrate increased stability and have uniform sizes. Microbubbles found in commercial preparations of ultrasound contrast agents (UCA) have very uniform sizes about that of a red blood cell. This property enables the bubbles to circulate through the pulmonary capillaries, hence to be visualized in arterial beds. Although some initial concerns were raised, UCA can now be considered safe after post-marketing experience from over 1 million patients has been reported $[68,69]$.

Blood flow quantification using contrast-enhanced ultrasound was first described by Wei et al. [70] in a canine model. The same technique was used by Kishimoto et al. to measure renal blood flow, demonstrating a good correlation with changes in renal blood flow as estimated by PAH clearance [71]. Schwenger [72] and Benozzi [73] et al. demonstrated that contrast-enhanced ultrasound was able to distinguish acute rejection from acute tubular necrosis. Another study, in healthy 


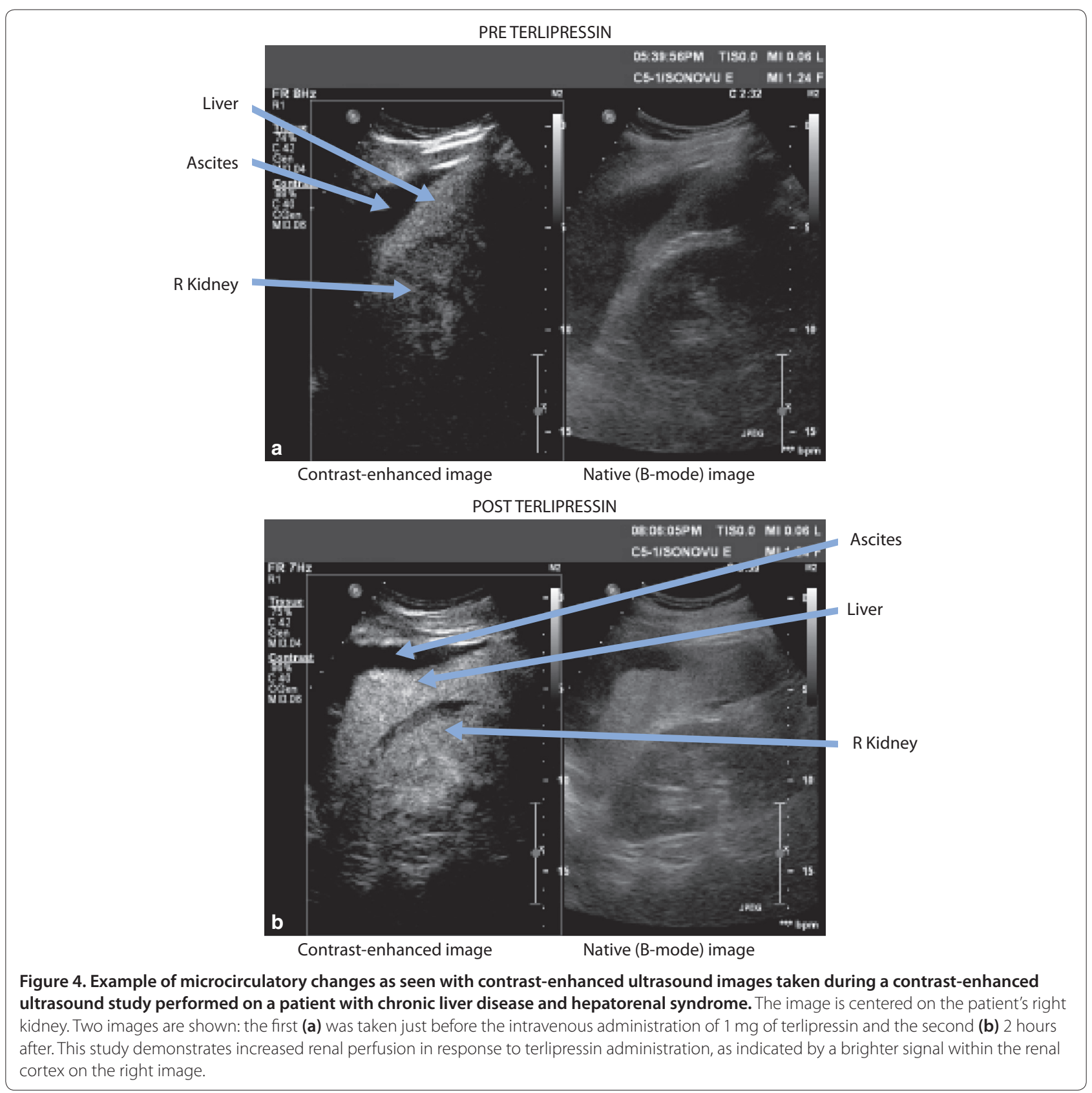

volunteers demonstrated that contrast-enhanced ultrasound was able to detect a $20 \%$ decrease in renal blood flow as induced by an angiotensin II infusion [74]. Above all, contrast-enhanced ultrasound can provide real time visualization of the renal microcirculation. Because it is very well tolerated and can be applied at the bedside, it could in theory be used to determine changes in microcirculation after therapeutic interventions. This would enable us to better understand the intra-renal microcirculatory changes following our common interventions and potentially drive our practice in patients at risk of AKI. As an example, as illustrated in Figure 4, contrast-enhanced ultrasound was able to confirm a strong microcirculatory response to terlipressin in a patient with hepatorenal syndrome.

Although in its early stages of validation, contrastenhanced ultrasound seems to be a promising technique to evaluate renal perfusion in critical illness. Indeed, it can be performed at the bedside, is minimally invasive and safe. Contrast-enhanced ultrasound provides information on the microcirculation and, potentially, could improve our understanding of flow alterations in critical illness associated AKI. 


\section{Conclusion}

Assessment of renal blood flow is important but difficult in AKI. Most techniques are not applicable at the bedside and require extensive patient manipulation, which, in the critically ill patient greatly reduces the practical applicability of any given technique. Furthermore, most techniques only enable global organ flow estimation, whereas information on the microcirculation is perhaps more likely to be useful in understanding the pathogenesis of AKI. Contrast-enhanced ultrasound is the first technique to overcome most of these limitations. Contrast-enhanced ultrasound may soon play a significant role in our ability to investigate microcirculatory changes in AKI.

\section{Competing interests}

The authors have received echo-contrast material for contrast enhanced ultrasound for the purpose of research by Bracco Pty Ltd, free of charge.

\section{List of abbreviations used}

AKI: acute kidney injury; ASL: arterial spin labelling; BOLD: blood oxygen leveldependent; CT: computed tomography; DTPA: diethylenetriaminepentaacetic acid; ERPF: estimate of the renal plasma flow; FDG: fluorodeoxyglucose; GFR: glomerular filtration rate; ICU: intensive care unit; MAP: mean arterial pressure; MRI: magnetic resonance imaging; $\mathrm{OlH}$ : orthiodohippurate; $\mathrm{PAH}$ : paraaminohippurate; PET: positron-emission tomography; RI: resistive index; RRT: renal replacement therapy; Tc-Mag: Tc-mercapto-acetylglycyl-glycyl-glycine; UCA: ultrasound contrast agents; USPIO: ultra-small particles of iron oxide.

\section{Author details}

'Department of Intensive Care, Austin Health, Heidelberg, Melbourne, Australia. ${ }^{2}$ Department of Radiology, Austin Health, Heidelberg, Melbourne, Australia. ${ }^{3}$ Australian and New Zealand Intensive Care research Centre, Department of Epidemiology and Preventive Medicine, Monash University, Melbourne, Australia.

Published: 19 March 2013

\section{References}

1. Uchino S, Kellum JA, Bellomo R, Doig GS, Morimatsu H, Morgera S, Schetz M Tan I, Bouman C, Macedo E, Gibney N, Tolwani A, Ronco C, Beginning and Ending Supporting Therapy for the Kidney (BEST Kidney) Investigators: Acute renal failure in critically ill patients: a multinational, multicenter study. JAMA 2005, 294:813-818.

2. Bagshaw SM, George C, Dinu I, Bellomo R: A multi-centre evaluation of the RIFLE criteria for early acute kidney injury in critically ill patients. Nephrol Dial Transplant 2008, 23:1203-1210.

3. Chertow GM, Levy EM, Hammermeister KE, Grover F, Daley J: Independent association between acute renal failure and mortality following cardiac surgery. Am J Med 1998, 104:343-348.

4. Parikh A, Shaw A: The economics of renal failure and kidney disease in critically ill patients. Crit Care Clin 2012, 28:99-111.

5. Bywaters EG, Beall D: Crush injuries with impairment of renal function. BMJ 1941, 1:427-432

6. Darmady EM: Renal anoxia and the traumatic uraemia syndrome. Br J Surg 1947, 34:262-271.

7. Schrier RW, Wang W: Acute renal failure and sepsis. N Engl J Med 2004 351:159-169.

8. Prowle JR, Ishikawa K, May CN, Bellomo R: Renal blood flow during acute renal failure in man. Blood Purif 2009, 28:216-225.

9. Ishikawa K, Calzavacca P, Bellomo R, Bailey M, May CN: Effect of selective inhibition of renal inducible nitric oxide synthase on renal blood flow and function in experimental hyperdynamic sepsis. Crit Care Med 2012 40:2368-2375.

10. Morimatsu H, Ishikawa K, May CN, Bailey M, Bellomo R: The systemic and regional hemodynamic effects of phenylephrine in sheep under normal conditions and during early hyperdynamic sepsis. Anesth Analg 2012, 115:330-342.
11. O'Connor PM, Evans RG: Structural antioxidant defense mechanisms in the mammalian and nonmammalian kidney: different solutions to the same problem? Am J Physiol Reg Integ Comp Physiol 2010, 299:R723-R727.

12. Rudolph AM, Heymann MA: Validation of the antipyrine method for measuring fetal umbilical blood flow. Circ Res 1967, 21:185-190.

13. McDevitt DG, Nies AS: Simultaneous measurement of cardiac output and its distribution with microspheres in the rat. Cardiovasc Res 1976, 10:494-498.

14. Mendell PL, Hollenberg NK: Cardiac output distribution in the rat: comparison of rubidium and microsphere methods. Am J Physiol 1971 221:1617-1620.

15. Prinzen FW, Bassingthwaighte JB: Blood flow distributions by microsphere deposition methods. 2000, Cardiovasc Res 45:13-21.

16. Leivestad T, Brodwall EK, Simonsen S: Determination of renal blood flow by thermodilution method. Scand J Clin Lab Invest 1978, 38:495-499.

17. Hornych A, Brod J, Slechta V: The measurement of the renal venous outflow in man by the local thermodilution method. Nephron 1971, 8:17-32.

18. Brenner M, Schaer GL, Mallory DL, Suffredini AF, Parrillo JE: Detection of renal blood flow abnormalities in septic and critically ill patients using a newly designed indwelling thermodilution renal vein catheter. Chest 1990, 98:170-179

19. Sward K, Valsson F, Sellgren J, Ricksten SE: Bedside estimation of absolute renal blood flow and glomerular filtration rate in the intensive care unit. A validation of two independent methods. Intensive Care Med 2004, 30:1776-1782.

20. Sward K, Valsson F, Sellgren J, Ricksten SE: Differential effects of human atrial natriuretic peptide and furosemide on glomerular filtration rate and renal oxygen consumption in humans. Intensive Care Med 2005, 31:79-85.

21. Redfors B, Bragadottir G, Sellgren J, Sward K, Ricksten SE: Effects of norepinephrine on renal perfusion, filtration and oxygenation in vasodilatory shock and acute kidney injury. Intensive Care Med 2011, 37:60-67.

22. Redfors B, Bragadottir G, Sellgren J, Sward K, Ricksten SE: Dopamine increases renal oxygenation: a clinical study in post-cardiac surgery patients. Acta Anaesthesio/ Scand 2010, 54:183-190.

23. Hollenberg NK, Adams DF, Solomon H, Chenitz WR, Burger BM, Abrams HL, Merrill JP: Renal vascular tone in essential and secondary hypertension: hemodynamic and angiographic responses to vasodilators. Medicine 1975 54:29-44.

24. Hollenberg NK, Sandor T: Vasomotion of renal blood flow in essential hypertension. Oscillations in xenon transit. Hypertension 1984, 6:579-585.

25. Hollenberg NK, Sandor T, Holtzman E, Meyerovitz MF, Harrington DP: Renal vasomotion in essential hypertension: influence of vasodilators. Hypertension 1989, 14:9-13.

26. Elkayam U, Mehra A, Cohen GTummala PP, Karaalp IS, Wani OR, Canetti M: Renal circulatory effects of adenosine in patients with chronic heart failure. J Am Coll Cardiol 1998, 32:211-215.

27. Doucette JW, Corl PD, Payne HM, Flynn AE, Goto M, Nassi M, Segal J: Validation of a Doppler guide wire for intravascular measurement of coronary artery flow velocity. Circulation 1992, 85:1899-1911.

28. Fritzberg AR, Kasina S, Eshima D, Johnson DL: Synthesis and biological evaluation of technetium-99 m MAG3 as a hippuran replacement. J Nucl Med 1986, 27:111-116.

29. Itoh K: 99mTc-MAG3: review of pharmacokinetics, clinical application to renal diseases and quantification of renal function. Ann Nucl Med 2001 15:179-190.

30. Trejtnar F, Laznicek M: Analysis of renal handling of radiopharmaceuticals. Q J Nucl Med 2002, 46:181-194.

31. Hilson AJ, Maisey MN, Brown CB, Ogg CS, Bewick MS: Dynamic renal transplant imaging with Tc-99 m DTPA (Sn) supplemented by a transplant perfusion index in the management of renal transplants. J Nucl Med 1978, 19:994-1000.

32. Peters AM, Gunasekera RD, Lavender JP, Myers MJ, Gordon I, Ash JM, Gilday DL: Noninvasive measurement of renal blood flow using DTPA. Contrib Nephrol 1987, 56:26-30.

33. Jafri RA, Britton KE, Nimmon CC, Solanki K, Al-Nahhas A, Bomanji J, Fettich J, Hawkins LA: Technetium-99 m MAG3, a comparison with iodine-123 and iodine-131 orthoiodohippurate, in patients with renal disorders. J NuCl Med 1988, 29:147-158.

34. Verbruggen AM, Nosco DL, Van Nerom CG, Bormans GM, Adriaens PJ, De Roo MJ: Technetium-99 m-L,L-ethylenedicysteine: a renal imaging agent. 
I. Labeling and evaluation in animals. J Nucl Med 1992, 33:551-557.

35. Gates GF: Glomerular filtration rate: estimation from fractional renal accumulation of 99mTc-DTPA (stannous). AJR Am J Roentgenol 1982, 138:565-570.

36. Fawdry RM, Gruenewald SM, Collins LT, Roberts AJ: Comparative assessment of techniques for estimation of glomerular filtration rate with $99 \mathrm{mTC}-$ DTPA. Eur J Nucl Med 1985, 11:7-12.

37. Haufe SE, Riedmuller K, Haberkorn U: Nuclear medicine procedures for the diagnosis of acute and chronic renal failure. Nephron Clin Pract 2006, 103:C77-c84.

38. Mullani NA, Ekas RD, Marani S, Kim EE, Gould KL: Feasibility of measuring first pass extraction and flow with rubidium-82 in the kidneys. Am J Physiol Imaging 1990, 5:133-140.

39. Tamaki N, Rabito CA, Alpert NM, Yasuda T, Correia JA, Bartai-Kovach M, Kanke M, Dragotakes SC, Strauss HW: Serial analysis of renal blood flow by positron tomography with rubidium-82. Am J Physiol 1986, 251:H1024-H1030.

40. Szabo Z, Xia J, Mathews WB, Brown PR: Future direction of renal positron emission tomography. Semin Nucl Med 2006, 36:36-50.

41. Juillard L, Janier MF, Fouque D, Lionnet M, Le Bars D, Cinotti L, Bathez P, Gharib C, Laville M: Renal blood flow measurement by positron emission tomography using 150-labeled water. Kidney Int 2000, 57:2511-2518.

42. Alpert NM, Rabito CA, Correia DJ, babich JW, Littman BH, Tompkins RG, Rubin NT, Rubin RH, Fischman AJ: Mapping of local renal blood flow with PET and H(2)(15)O. J Nucl Med 2002, 43:470-475.

43. Vallee JP, Lazeyras F, Khan HG, Terrier F: Absolute renal blood flow quantification by dynamic MRI and Gd-DTPA. Eur Radiol 2000, 10:1245-1252.

44. Marckmann P, Skov L, Rossen K, Dupont MB, Heaf JG, Thomson HS: Nephrogenic systemic fibrosis: suspected causative role of gadodiamide used for contrast-enhanced magnetic resonance imaging. J Am SoC Nephrol 2006, 17:2359-2362

45. Perazella MA: Current status of gadolinium toxicity in patients with kidney disease. Clin J Am Soc Nephrol 2009, 4:461-469.

46. Neuwelt EA, Hamilton BE, Varallyay CG, Rooney WR, Edelman RD, Jacobs PM, Watnick SG: Ultrasmall superparamagnetic iron oxides (USPIOs): a future alternative magnetic resonance (MR) contrast agent for patients at risk for nephrogenic systemic fibrosis (NSF)? Kidney Int 2009, 75:465-474.

47. Debatin JF, Ting RH, Wegmuller $\mathrm{H}$, Sommer FG, Fredrickson JO, Brosnan TJ, Myers BD, Herfkens RJ, Pelc NJ: Renal artery blood flow: quantitation with phase-contrast MR imaging with and without breath holding. Radiology 1994, 190:371-378.

48. Sommer G, Corrigan G, Fredrickson J, Sawyer-Glover A, Liao JR, Myers B, Pelc $\mathrm{N}$ : Renal blood flow: measurement in vivo with rapid spiral MR imaging Radiology 1998, 208:729-734

49. Prowle JR, Molan MP, Hornsey E, Bellomo R: Cine phase-contrast magnetic resonance imaging for the measurement of renal blood flow. Contrib Nephrol 2010, 165:329-336.

50. Wolf RL, King BF, Torres VE, Wilson DM, Ehman RL: Measurement of normal renal artery blood flow: cine phase-contrast MR imaging vs clearance of p-aminohippurate. AJR Am J Roentgenol 1993, 161:995-1002.

51. de Haan MW, Kouwenhoven M, Kessels AG, van Engelshoven JM: Renal artery blood flow: quantification with breath-hold or respiratory triggered phase-contrast MR imaging. Eur Radiol 200, 10:1133-1137.

52. King BF, Torres VE, Brummer ME, Chapman AB, Bae KT, Glockner JF, Arya K Felmlee JP, Grantham JJ, Guay-Woodford LM, Bennett WM, Klahr S, Hirschman GH, Kimmel PL, Thompson PA, Miller JP, Consortium for Radiologic Imaging Studies of Polycystic Kidney Disease (CRISP): Magnetic resonance measurements of renal blood flow as a marker of disease severity in autosomal-dominant polycystic kidney disease. Kidney Int 2003, 64:2214-2221

53. Prowle JR, Molan MP, Hornsey E, Bellomo R: Measurement of renal blood flow by phase-contrast magnetic resonance imaging during septic acute kidney injury: a pilot investigation. Crit Care Med 2012, 40:1768-1776.

54. Golay X, Hendrikse J, Lim TC: Perfusion imaging using arterial spin labeling. Top Magn Reson Imaging 2004, 15:10-27.

55. Artz NS, Sadowski EA, Wentland AL, Grist TM, Seo S, Djamali A, Fain SB Arterial spin labeling MRI for assessment of perfusion in native and transplanted kidneys. Magn Reson Imaging 2011, 29:74-82.

56. Spuentrup E, Manning WJ, Bornert P, Kissinger KV, Botnar RM, Stuber M: Renal arteries: navigator-gated balanced fast field-echo projection MR angiography with aortic spin labeling: initial experience. Radiology 2002, 225:589-596.
57. Ritt M, Janka R, Schneider MP, Martirosian P, Hornegger J, Bautz W, Uder M, Schmieder RE: Measurement of kidney perfusion by magnetic resonance imaging: comparison of MRI with arterial spin labeling to paraaminohippuric acid plasma clearance in male subjects with metabolic syndrome. Nephrol Dial Transplant 2010, 25:1126-1133.

58. Fenchel M, Martirosian P, Langanke J, Giersch J, Miller S, Stauder NI, Kramer U, Caussen CD, Schick F: Perfusion MR imaging with FAIR true FISP spin labeling in patients with and without renal artery stenosis: initial experience. Radiology 2006, 238:1013-1021.

59. Textor SC, Glockner JF, Lerman LO, Misra S, McKusick MA, Riederer SJ, Grandle $\mathrm{JP}$, Gomex SI, Romero JC: The use of magnetic resonance to evaluate tissue oxygenation in renal artery stenosis. J Am Soc Nephrol 2008, 19:780-788.

60. Warner L, Glockner JF, Woollard J, Textor SC, Romero JC, Lerman LO: Determinations of renal cortical and medullary oxygenation using blood oxygen level-dependent magnetic resonance imaging and selective diuretics. Invest Radio/ 2011, 46:41-47.

61. Pruijm M, Hofmann L, Maillard M, Tremblay S, Glatz N, Wuerzner G, Burnier M, Vogt B: Effect of sodium loading/depletion on renal oxygenation in young normotensive and hypertensive men. Hypertension 2010, 55:1116-1122.

62. Heine GH, Gerhart MK, Ulrich C, Kohler H, Girndt M: Renal Doppler resistance indices are associated with systemic atherosclerosis in kidney transplant recipients. Kidney Int 2005, 68:878-885.

63. Wan L, Yang N, Hiew CY, Schelleman A, Johnson L, May C, Bellomo R: An assessment of the accuracy of renal blood flow estimation by Doppler ultrasound. Intensive Care Med 2008, 34:1503-1510.

64. Lerolle N, Guerot E, Faisy C, Bornstain C, Diehl JL, Fagon JY: Renal failure in septic shock: predictive value of Doppler-based renal arterial resistive index. Intensive Care Med 2006, 32:1553-1559.

65. Rodrigo E, Lopez-Rasines G, Ruiz JC, Lastra P, Gómez-Dermitt V, GómezAlamillo C, González-Coturruelo J, Calabia A, Arias M: Determinants of resistive index shortly after transplantation: independent relationship with delayed graft function. Nephron Clin Pract 2010, 114:c178-186.

66. Schneider A, Johnson L, Goodwin M, Schelleman A, Bellomo R: Bench-tobedside review: Contrast enhanced ultrasonography - a promising technique to assess renal perfusion in the ICU. Crit Care 2011, 15:157.

67. Romero JR, Frey JL, Schwamm LH, Damaerschalk BM, Chaliki HP, Parikh G, Burke RF, Babikian VL: Cerebral ischemic events associated with "bubble study" for identification of right to left shunts. Stroke 2009, 40:2343-2348.

68. Main ML, Ryan AC, Davis TE, Albano MP, Kusnetzky LL, Hibberd M: Acute mortality in hospitalized patients undergoing echocardiography with and without an ultrasound contrast agent (multicenter registry results in 4,300,966 consecutive patients). Am J Cardiol 2008, 102:1742-1746.

69. Dolan MS, Gala SS, Dodla S, Abdelmoneim SS, Xie F, Cloutier D, Bierig M, Mulvagh SL, Porter TR, Labovita AJ: Safety and efficacy of commercially available ultrasound contrast agents for rest and stress echocardiography a multicenter experience. J Am Coll Cardiol 2009, 53:32-38.

70. Wei K, Jayaweera AR, Firoozan S, Linka A, Skyba DM, Kaul S: Quantification of myocardial blood flow with ultrasound-induced destruction of microbubbles administered as a constant venous infusion. Circulation 1998, 97:473-483.

71. Kishimoto N, Mori Y, Nishiue T, Shibasaki Y, Iba O, Nose A, Uchiyama-Tanaka Y, Masaki H, Katsubara H, Iwasaka T: Renal blood flow measurement with contrast-enhanced harmonic ultrasonography: evaluation of dopamineinduced changes in renal cortical perfusion in humans. Clin Nephrol 2003, 59:423-428.

72. Schwenger V, Korosoglou G, Hinkel UP, Morath C, Hansen A, Sommerer C, Dikow R, Hardt S, Schmidt J, Kücherer H, Katus HA, Zeier M: Real-time contrast-enhanced sonography of renal transplant recipients predicts chronic allograft nephropathy. Am J Transplant 2006, 6:609-615.

73. Benozzi L, Cappelli G, Granito M, Davoli D, Favali D, Montecchi MG, Grossi A, Torricelli P, Albertazzi A: Contrast-enhanced sonography in early kidney graft dysfunction. Transplant Proc 2009, 41:1214-1215.

74. Schneider AG, Hofmann L, Wuerzner G: Renal perfusion evaluation with contrast-enhanced ultrasonography. Nephrol Dial Transplant 2012, 27:674-681.

75. Textor SC, Lerman L: Renovascular hypertension and ischemic nephropathy: state of the art. Am J Hypertens 2010, 23:1159-1169.

\section{doi:10.1186/cc12529}

Cite this article as: Schneider AG, et al: Measurement of kidney perfusion in critically ill patients. Critical Care 2013, 17:220. 